\title{
Retrospective Study: Malassezia Folliculitis Profile
}

\author{
Putri Intan Primasari, Evy Ervianti \\ Departement of Dermatology and Venereology \\ Faculty of Medicine Universitas Airlangga/Dr. Soetomo General Academic Teaching Hospital \\ Surabaya
}

\begin{abstract}
Background: Malassezia folliculitis (MF) is a chronic infectious disease of pilosebaceous follicles caused by Malassezia $s p$. Clinical features of MF include erythematous papules and itchy perifollicular pustules, especially on the upper body, neck, upper arms, and face. The disease is usually reported on adolescents. Objective: To evaluate the profile of MF patients in four years (2014-2017) period in the Mycology Division of Dermatovenerology Outpatient Clinic of Dr. Soetomo General Academic Hospital Surabaya. Methods: This study was a retrospective study to examine the medical records of MF patients in the Mycology Division of Dermatovenerology Outpatient Clinic General Academic Hospital Dr. Soetomo Surabaya from January 2014 to December 2017. Results: The number of new MF patient visits during 2014-2017 was 196 patients, and the average annual visit was 55 patients in 2014, 49 patients in 2015, 65 patients in 2016, and 27 patients in 2017. The majority of patients were males, were aged 15-24 years old. The chief complaint was reddish papules accompanied by moderate itching in the predilection area and most often found in the upper body. The Wood's lamp examination revealed greenish-yellow color, and $20 \% \mathrm{KOH}$ examination showed spores. Most systemic therapies was ketoconazole and tretinoin $0.05 \%$ cream for topical therapy. Conclusions: There was a decrease in the number of MF patients. The diagnoses of MF were based on history taking, physical examination, $20 \% \mathrm{KOH}$, and Wood's lamp.
\end{abstract}

Keywords: retrospectives studies, Malassezia sp., malassezia folliculitis.

Correspondence address: Evy Ervianti, Department of Dermatology and Venereology, Faculty of Medicine, Universitas Airlangga, Dr. Soetomo General Academic Teaching Hospital, Jl. Prof. Dr. Moestopo No. 6- 8 Surabaya 60131, Indonesia. Phone: +621332681513, e-mail: evy_if@yahoo.co.id.

\section{INTRODUCTION}

Malassezia folliculitis (MF) is a chronic infection of follicular pilosebaceous caused by fungus Malassezia $s p$. MF is often misdiagnosed as acne vulgaris (AV) because the clinical features of MF are similar to AV in the form of erythematous papules and itchy perifollicular pustules, especially in the upper body, neck, upper arms, and face. Malassezia sp. is a lipophilic fungus that is mostly found in hair follicles and stratum corneum. MF results from the excessive growth of the fungus Malassezia sp., which is a normal flora on the skin. This disorder arises in certain conditions that may change the normal flora, such as immunosuppression condition or long-term antibiotic consumption. ${ }^{1,2}$

The development of MF is associated with the presence of high temperatures and humidity. Thus, this MF case is mostly found in tropical countries. Colonization by Malassezia sp. begins immediately after birth with the highest incidence in teenagers and young adults. There was no difference in incidence in terms of race or sex. ${ }^{3}$ Study of 49 patients in Turkey by Durdu et al (2012) showed that the most common age group affected by MF was 26 years. ${ }^{4}$ A study from America by Brea et al in 2010-2015 involving 110 patients showed that MF mostly affects patients with the mean age group of 15 years old. ${ }^{5}$ The prevalence of $\mathrm{MF}$ in Indonesia in the general population is still unknown. Research conducted by Pravitasari in the Mycology Division of Outpatient Clinic of Dr. Soetomo General Academic Hospital Surabaya for three months from October 2014 to January 2015 found that there were 36 patients with the most age group 15-24 years. $^{6}$

The diagnosis of MF is based on history taking and physical examination as well as microscopic examination of fungi. Diagnostic criteria for clinical symptoms include follicular dome of $2-3 \mathrm{~mm}$ in size with central delle accompanied by pustules. The distribution of MF is quite typical. It mostly occurred the body, such as the back, chest, and upper arms. Besides, confirmation by microscopic examination of the fungus is also needed. It is done by collecting specimens from pustules, dropping $20 \% \mathrm{KOH}$ liquid with a blue-black ink parker, and viewing under a microscope. The result will show blastospores. Clinical Grade is used for the following assessment system are grade 0 clean or provided some open and closed comedones, not inflamed, negative $\mathrm{KOH}$, grade $1+$ molluscoid papule blackheads and non-inflammatory, 
grade $2+$ molluscoid papule blackheads and inflammation, grade $3+$ cysts, nodules and papulopustulesMany topical or systemic treatment options are available for MF treatment, depending on the symptoms and severity. However, many patients do not receive appropriate treatment due to a lack of awareness, misdiagnosis, and non-compliance with prescribed drugs. ${ }^{1,2,3,7}$

This retrospective study was made to evaluate MF disease in the Mycology Division of the Outpatient Clinic of Dermatovenerology Departement Dr. Soetomo General Academic Hospital Surabaya from 2014 to 2017 (4 years). The aims for this retrospective study was to provide data of diagnosis, selection of therapies, and prevention, therefore expected to increase the success of MF management in the Mycology Division of the Outpatient Clinic of Dermatovenerology Department Dr. Soetomo General Academic Hospital Surabaya.

\section{RESEARCH METHODS}

This was a descriptive retrospective study, and it was conducted by reviewing the medical records of MF patients in the Mycology Division of Outpatient Clinic of Dermatovenerology Department Dr. Soetomo General Academic Hospital Surabaya between January 2014 and December 2017. The reviewing process evaluated the new MF patients based on history, clinical feature, diagnosis, management, and follow up visite.

\section{RESULTS}

The number of MF new patient visits in the Mycology Division Outpatient Clinic of Dermatovenerology Department Dr. Soetomo General
Academic Hospital Surabaya over four years (2014 2017) was 196 patients, contributing $22.4 \%$ of the patients in Mycology Division Outpatient Clinic of Dermatovenerology Department Dr. Soetomo General Academic Hospital Surabaya or 2\% of 9796 patients who visited the Dermatovenerology Department Outpatient Clinic Dr. Soetomo General Academic Hospital Surabaya. The annual number of MF new patient visits compared to all new patients in the Mycology Division Outpatient Clinic of Dermatovenerology Department Dr. Soetomo General Academic Hospital Surabaya was 55 (23.4\%) patients in 2014, $49(30 \%)$ patients in 2015, $65(26.1 \%)$ patients in 2016, and 27 (12.2\%) patients in 2017. Most new MF patients were in the 15-24 years age group are 129 patients $(65.8 \%)$. The least new MF patients were in 65 years of age group $(0.5 \%)$ and $1-4$ years age group $(0 \%)$. The number of male patients was higher than the female patients, totaling 125 female patients $(63.8 \%)$. Table 1 shows that the chief complaint of patients was pimple redness and itchy, and they affected all patients or equal to 196 patients (100\%). Table 2 shows the degree of itch. There were 184 patients $(93.9 \%)$ who complained of moderate itch.

Tables 3 and 4 show the major distribution of MF patient lesions in the Mycology Division Outpatient Clinic of Dermatovenerology Department Academic General Hospital Dr. Soetomo from 2014 to 2017. MF was found on the trunk area of 75 patients $(38.26 \%)$, the back area in 65 patients $(33.16 \%)$. Most clinicalgrade examination results were grade $2+$, affecting 168 $(85.7 \%)$ patients, and the lowest clinical-grade examination result was grade $1+$, affecting $5(2.55 \%)$ patients.

Table 1. Distribution of the chief complaints of new MF patients in the Mycology Division Outpatient Clinic of Dermatovenerology Department Dr. Soetomo General Academic Hospital Surabaya from 2014 to 2017.

\begin{tabular}{|c|c|c|c|c|c|}
\hline \multirow{2}{*}{ Complaint } & \multicolumn{4}{|c|}{ Year } & \multirow{2}{*}{$\begin{array}{l}\text { Total }(\%) \\
n=196\end{array}$} \\
\hline & $2014(\%) n=55$ & $2015(\%) n=49$ & $2016(\%) n=65$ & $\begin{array}{l}2017(\%) \\
n=27\end{array}$ & \\
\hline Itchy & $55(100)$ & $49(100)$ & $65(100)$ & $27(100)$ & $196(100)$ \\
\hline Reddish Pustule & $55(100)$ & $49(100)$ & $65(100)$ & $27(100)$ & $196(100)$ \\
\hline Pustule with boils & $11(20)$ & $4(8.2)$ & $1(1.5)$ & $1(2)$ & $17(8.7)$ \\
\hline Reddish spots & $3(5.4)$ & $10(20.4)$ & $3(4.6)$ & 0 & $16(8.2)$ \\
\hline White patches & 0 & $1(2)$ & 0 & 0 & $1(0.5)$ \\
\hline Black/ brownish spots & $3(5.4)$ & $1(2)$ & $3(4)$. & $1(2)$ & $8(4.1)$ \\
\hline Thin white scales & 0 & $1(2)$ & 0 & 0 & $1(0.5)$ \\
\hline
\end{tabular}


Table 2. Distribution of itch degree of new MF patients in the Mycology Division Outpatient Clinic of Dermatovenerology Department Dr. Soetomo General Academic Hospital Surabaya from 2014 to 2017.

\begin{tabular}{llllll}
\hline \multirow{2}{*}{ The degree of itch } & \multicolumn{5}{c}{ Year } \\
\cline { 2 - 6 } & 2014 & 2015 & 2016 & 2017 & Total (\%) \\
\hline Mild & 0 & 0 & 0 & 0 & 0 \\
Moderate & 52 & 48 & 59 & 25 & $184(93.9)$ \\
Severe & 3 & 1 & 6 & 2 & $12(6.1)$ \\
\hline Total & 55 & 49 & 65 & 27 & $196(100)$ \\
\hline
\end{tabular}

Table 3. Distribution/Location of MF patient lesions in the Mycology Division Outpatient Clinic of Dermatovenerology Department Dr. Soetomo General Academic Hospital Surabaya from 2014 to 2017.

\begin{tabular}{lcccrr}
\hline \multirow{2}{*}{ Location of the lesion } & \multicolumn{3}{c}{ Year } & \multirow{2}{*}{ Total (\%) } \\
\cline { 2 - 5 } & 2014 & 2015 & 2016 & 2017 & $75(38.26)$ \\
\hline Trunk & 21 & 20 & 22 & 12 & $65(33.16)$ \\
Back & 12 & 14 & 28 & 11 & $25(12.8)$ \\
Upper body and arms & 14 & 6 & 5 & 0 & $21(10.71)$ \\
Body and face & 4 & 5 & 8 & 4 & $6(3.06)$ \\
Face & 1 & 3 & 2 & 0 & $4(2.04)$ \\
Body, upper arm, face & 3 & 1 & 0 & 0 & $196(100)$ \\
\hline Total & 55 & 49 & 65 & 27 & \\
\hline
\end{tabular}

Table 4. Distribution of clinical-grade of MF patient lesions in the Mycology Division Outpatient Clinic of Dermatovenerology Department Dr. Soetomo General Academic Hospital Surabaya from 2014 to 2017.

\begin{tabular}{|c|c|c|c|c|c|}
\hline \multirow{2}{*}{ Grade } & \multicolumn{3}{|c|}{ Year } & & \multirow{2}{*}{$\begin{array}{c}\text { Total }(\%) \\
\mathrm{n}=196\end{array}$} \\
\hline & $2014(\%)$ & $2015(\%)$ & $2016(\%)$ & $2017(\%)$ & \\
\hline Grade 0 & 0 & 0 & 0 & 0 & 0 \\
\hline Grade 1 & $1(4)$ & $1(2.1)$ & $2(3.1)$ & $1(3.7)$ & $5(2.55)$ \\
\hline Grade 2 & $44(80)$ & $41(83.6)$ & $58(89.2)$ & $25(92.6)$ & $168(85.7)$ \\
\hline Grade 3 & $10(16)$ & $7(14.3)$ & $5(7.7)$ & $1(3.7)$ & $23(11.75)$ \\
\hline Total & $55(100)$ & $49(100)$ & $65(100)$ & $27(100)$ & $196(100)$ \\
\hline
\end{tabular}

Table 5. Distribution of predisposing factors for MF patients in the Mycology Division Outpatient Clinic of Dermatovenerology Department Dr. Soetomo General Academic Hospital Surabaya from 2014 to 2017.

\begin{tabular}{|c|c|c|c|c|c|}
\hline \multirow{2}{*}{$\begin{array}{l}\text { Predisposing } \\
\text { Factors }\end{array}$} & \multicolumn{4}{|c|}{ Year } & \multirow{2}{*}{ Total $(n=195)$} \\
\hline & $2014(\%)$ & $2015(\%)$ & $2016(\%)$ & $2017(\%)$ & \\
\hline \multicolumn{6}{|l|}{ Endogenous } \\
\hline Without endogenous factors & 32 & 29 & 42 & 19 & $122(62.2)$ \\
\hline There is no data & 13 & 3 & 16 & 2 & $30(15.3)$ \\
\hline Corticosteroids & 4 & 11 & 4 & 2 & $21(10.7)$ \\
\hline Antibiotics & 2 & 5 & 3 & 1 & $11(., 6)$ \\
\hline Pregnant & 0 & 2 & 0 & 0 & $2(1.02)$ \\
\hline Malignancy & 2 & 0 & 0 & 2 & $4(2.04)$ \\
\hline HIV & 1 & 0 & 0 & 0 & $1(0.5)$ \\
\hline Diabetes mellitus & 1 & 0 & 0 & 0 & $1(0.5)$ \\
\hline \multicolumn{6}{|l|}{ Exogenous } \\
\hline There is no data & 24 & 22 & 24 & 8 & $78(39.8)$ \\
\hline Without exogenous factors & 17 & 5 & 17 & 12 & $51(26.02)$ \\
\hline Body lotion & 6 & 12 & 14 & 4 & $36(18.4)$ \\
\hline Tight clothes & 5 & 9 & 9 & 2 & $25(12.8)$ \\
\hline Hygiene & 3 & 1 & 1 & 1 & $6(3.06)$ \\
\hline
\end{tabular}


Table 5 shows that the highest number of MF patients without endogenous predisposing factors was $122(62.2 \%)$. There were $30(15.3 \%)$ MF patients without data on endogenous predisposing factors. Endogenous predisposing factors were corticosteroid use in $21(10.7 \%)$ patients and antibiotic use in 11 $(5.6 \%)$ patients. For exogenous predisposing factors, there was a significant absence of literature sources that conclude the factors were related to MF patients, which were found in $78(39.8 \%)$ patients, and 51 (26.02\%) MF patients were found without exogenous predisposition factors. The most exogenous predisposing factor was the use of body lotion or moisturizer; it was found in $36(18.4 \%)$ patients.

Table 6 shows the results of $20 \% \mathrm{KOH}$ examination in the MF case. That reveal most patients were at grade $4(88.3 \%)$, while in table 7 the Woods Lamp examination shows that $70 \%$ has positive results with bright greenish-yellow color on $119(86.2 \%)$ patients, blue result on 19 (13.8\%) patients, and no patient showed white color.

Table 6. Laboratory examination of $20 \% \mathrm{KOH}$ of patients in the Mycology Division Outpatient Clinic of Dermatovenerology Department Dr. Soetomo General Academic Hospital Surabaya from 2014 to 2017.

\begin{tabular}{lccccc}
\hline \multirow{2}{*}{ Inspection Results } & \multicolumn{3}{c}{ Year } & \multirow{2}{*}{$\begin{array}{c}\text { Total }(\%) \\
\mathrm{n}=196\end{array}$} \\
\cline { 2 - 5 } & $2014(\%)$ & $2015(\%)$ & $2016(\%)$ & $2017(\%)$ & 0 \\
Blastopora grade 1 & 0 & 0 & 0 & 0 & $3(1.5)$ \\
Blastopora grade 2 & 0 & $1(2.0)$ & $2(3.1)$ & 0 & $20(10.2)$ \\
Blastopora grade 3 & $2(3.6)$ & $7(14.3)$ & $10(15.4)$ & $1(3.7)$ & $173(88.3)$ \\
Blastopora grade 4 & $53(96.4)$ & $41(83.7)$ & $53(81.5)$ & $26(96.3)$ & $196(100)$ \\
\hline Total & $55(100)$ & $49(100)$ & $65(100)$ & $27(100)$ & $196(\%)$ \\
\hline
\end{tabular}

Table 7. The results of Wood's Lamp examination on MF patients in the Mycology Division Outpatient Clinic of Dermatovenerology Department Dr. Soetomo General Academic Hospital Surabaya from 2014 to 2017.

\begin{tabular}{llllll}
\hline \multirow{2}{*}{ Inspection Results } & \multicolumn{3}{c}{ Year } & \multicolumn{1}{c}{$\begin{array}{c}\text { Total }(\%) \\
\mathrm{n}=196\end{array}$} \\
\cline { 2 - 5 } & $2014(\%)$ & $2015(\%)$ & $2016(\%)$ & $2017(\%)$ & $138(70)$ \\
Positive & $31(56)$ & $29(59)$ & $54(83)$ & $24(88)$ & \\
Color: & 26 & 25 & 47 & 21 & $119(86.2)$ \\
Bright greenish-yellow & 5 & 4 & 7 & 3 & $19(13.8)$ \\
Blue & 0 & 0 & 0 & 0 & 0 \\
White & $24(44)$ & $20(41)$ & $11(17)$ & $3(12)$ & $58(30)$ \\
Negative & $55(100)$ & $49(100)$ & $65(100)$ & $27(100)$ & $196(100)$ \\
\hline Total & & & & & \\
\hline
\end{tabular}

Table 8. Distribution of MF patient therapy in the Mycology Division Outpatient Clinic of Dermatovenerology Department Dr. Soetomo General Academic Hospital Surabaya from 2014 to 2017.

\begin{tabular}{llllll}
\hline Therapy & \multicolumn{4}{c}{ Year } & Total (\%) \\
\cline { 2 - 5 } & $2014(\%)$ & $2015(\%)$ & $2016(\%)$ & $2017(\%)$ & n=196 \\
\hline Systemic & $55(100)$ & $48(98)$ & $65(100)$ & $27(100)$ & $195(99)$ \\
$\begin{array}{l}\text { Ketoconazole 2x200mg } \\
\text { Itraconazole 200mg }\end{array}$ & 0 & $1(2)$ & 0 & 0 & $1(1)$ \\
$\begin{array}{l}\text { Fluconazole 200mg } \\
\text { Terbinafin }\end{array}$ & 0 & 0 & 0 & 0 & 0 \\
Topical & 0 & 0 & 0 & 0 & 0 \\
Ketoconazole 2\% Cream & 0 & 0 & 0 & 0 & 0 \\
Ketoconazole 2\% scalp solution & $1(1.8)$ & 0 & 0 & 0 & $1(1)$ \\
Miconazole cream & 0 & 0 & 0 & 0 & 0 \\
Selenium Sulfide & 0 & 0 & 0 & 0 & 0 \\
Tretinoin 0,025\% Cream & 0 & 0 & 0 & 0 & 0 \\
Tretinoin 0,05\% Cream & 0 & $3(6.1)$ & $3(4.6)$ & 0 & $6(3.06)$ \\
Tretinoin 0,1\% cream & 0 & 0 & 0 & 0 & 0 \\
\hline
\end{tabular}


Table 8 shows that ketoconazole is the most used therapeutic option used in MF cases in the Mycology Division Outpatient Clinic of Dermatology Venerology Department Dr. Soetomo General Academic Hospital Surabaya between 2014 and 2017. Furthermore, $0.05 \%$ tretinoin cream was obtained as the most adjuvant therapy to MF.

\section{DISCUSSION}

The number of new MF patient visits in the Mycology Division Outpatient Clinic of Dermatology Venerology Department Dr. Soetomo General Academic Hospital Surabaya between 2014 and 2017 was 196 patients, which is equal to $22.4 \%$ of the total 876 patients of Mycology Division or 2\% of 9796 patients who visited the Outpatient Clinic of Dermatology Venerology Department Dr. Soetomo General Academic Hospital Surabaya in between 2014 and 2017. The comparison of MF new patient visits to all new patients annually was $55(23.4 \%)$ patients in 2014, 49 (30\%) patients in 2015, 65 (26.1\%) patients in 2016, and $27(12.2 \%)$ patients in 2017. It showed that the number of new MF cases, in general, was decreasing. The decline might be promoted by the health insurance program in Indonesia named BPJS, enabling Indonesian citizens to access healthcare. The program requires the patients to be treated first at primary healthcare (Public health centre or nearest clinic). Dr. Soetomo General Academic Hospital Surabaya is a third level referral hospital. There has been no study of MF conducted in the Mycology Division Outpatient Clinic of Dermatology Venerology Dr. Soetomo General Academic Hospital Surabaya. Based on various literature, the incidence of MF is still unknown. Research conducted by Durdu et $a l$ in Adana and Hatay, Turkey, in May-August 2012 found that the MF prevalence in Turkey was $18.5 \%$. This might relate to the fact that MF cases are mostly found in tropical countries with high humidity. The high humidity resulting in increased sebum production, which promotes the growth of Malassezia sp. on the skin, and may disturb the skin barrier system. ${ }^{4}$

The most age groups affected by MF in the Mycology Division Outpatient Clinic of Dermatology Venerology Department Dr. Soetomo General Academic Hospital Surabaya was 15-24 years, which equals to $129(65.8 \%$ ) patients, followed by age group of 25-44 years, which equals to 47 (24\%) patients. Similar to the study conducted by Brea et al in the United States involving $110 \mathrm{MF}$ patients from 2010 to 2015, the result showed that MF cases were mostly reported on persons aged 15-24 years old. ${ }^{5}$ In previous studies, the peak prevalence of MF associated with androgen hormone activity, which can stimulate the activity of the sebaceous glands. Colonization by Malassezia $s p$. begins immediately after birth with its peak during adolescence and young adults, and this is related to the activity of the sebaceous glands. Considering the majority of the group is in productive age, with a high frequency of physical activity, this group has the tendency to sweat and to have moist skin, increasing the risk of getting MF. ${ }^{1,2,3}$

This retrospective study found that the ratio of male patients was greater than female patients. The ratio was $63.8 \%$ male and $36.2 \%$ female. These results were similar to the study conducted by Sharquie et al in Iraq between October 2008 and 2009. The study found that the majority of MF cases patients were male $(62.3 \%)$. Men are known to have longer activities outside, causing increased production of sweat and skin moisture, which is one of the predisposing factors for fungal growth. ${ }^{8}$

In this retrospective study, it was found that the chief complaints of MF patients in 2014-2017 were itching and reddish nodules $(100 \%)$. This is similar to the previous study, showing that MF can be accompanied by itch and red erythematous nodules. ${ }^{1,3,4,9}$ The degree of itch caused by MF was mostly moderate reported by 184 patients $(93 \%)$. This is similar to a case report by Poitr (2010) which stated that MF is always accompanied by persistent itching, and according to Rubenstein, the intensity of pruritus or itching was $79.6 \%$ or 49 patients. ${ }^{8,10}$

The distribution of MF patient lesions was mostly found on the trunk of 75 patients $(38.26 \%)$, followed by a back area of 65 patients $(33.16 \%)$ as well as the upper body and upper arms of 25 patients $(12.8 \%)$. This is consistent with the literature mentioned by Lee et al (2010), which stated that MF often occurs on the chest, back, shoulders, and rarely on the face. The results of this study indicate that MF is more frequently occur on the upper body and rarely found on the face because the facial area has relatively low humidity and temperature compared to other areas covered by clothes. ${ }^{11}$

The clinical-grade examination of MF patients showed the most common result was grade $2+$ with molluscoid papules and inflammation blackheads found in $168(85.7 \%)$ patients, and the lowest result was grade $1+$ found only in $5(2.55 \%)$ people. JacintoJamora (1991) showed that from 68 patients diagnosed with MF observed for 12 months, 66 patients had discrete skin lesions, polymorphs, follicular eruptions of 2-3 mm, an erythematous base (including grade $2+$ ), while several cases have papulopustular, nodules, and cysts. ${ }^{1,2,12}$

The predisposing factor is significant in triggering the MF symptoms. Based on the data, it was found that the highest number of MF patients have no 
endogenous predisposing factors, and this result was found in 122 patients $(62.2 \%)$, while antibiotic use was found in $11(5.6 \%)$ patients. For exogenous predisposing factors, $78(39.8 \%)$ patients have no data, and there were $51(26.02 \%)$ MF patients visited without exogenous predisposition factors. The exogenous predisposing factor that mostly found in our research subject was the use of body lotion or moisturizer, and it applied to $36(18.4 \%)$ patients. According to the literature, endogenous factors related to MF are immune suppression, such as the use of steroids, antibiotics, and immunosuppressants, diabetes mellitus, HIV infection, pregnancy, and malignancy. Although this factor does not directly affect the occurrence of MF infection, it can affect the immune system in responding to the infections. This study also showed that pregnancy might act as an endogenous factor. It was due to significant maternal physiological changes in pregnant women. Increased adrenocortical function and decreased maternal cellmediated immune responsiveness during pregnancy may contribute to the development of MF. The increase in hormones during pregnancy include adrenocortical hormones and sex hormones, which may increase the rate of basal metabolism in pregnant women. It may make pregnant women experience an excessive hot sensation, which eventually creates a supportive environment for Malassezia sp. to grow. Also, sebaceous gland activity increases during pregnancy and causes Malassezia sp. as lipophilic organisms to breed. Another endogenous factor was the use of antibiotics, which is a predisposing factor to $\mathrm{MF}$ because antibiotic suppresses the normal flora on the skin, increases the proliferation of Malassezia $s p .^{13}$ Exogenous predisposing factor such as tight clothes also plays an important role because tight, thick, and layered clothing in hot temperatures will create body heat which will increase the growth of Malassezia.sp. ${ }^{2}$

Predisposing factors for patients with MF may be a combination of many factors. The result showed that only $18.4 \%$ of patients used body lotion. This finding may suggest that it is common to apply body lotion to the upper body area and, most often, on hands and feet area. It is said that the use of body lotion results in occlusion of the skin and hair follicles, which triggers the growth of Malassezia sp. This will cause inflammation in the hair follicles due to increased free fatty acids. Many MF cases, endogenous and exogenous factors, are possibly caused by hot weather in tropical countries. Higher temperatures may increase the rate of sebum secretion to the skin surface, promoting Malassezia sp. to breed. ${ }^{2}$ A study in BasrahIraq in 2012 found that increment of MF cases was due to the country's hot and humid climate. This is consistent with the results of our study; that all samples were collected in Surabaya, which has hot and humid weather. ${ }^{8}$

Criteria for diagnoses in MF were based on the history of the main complaint, physical examination, direct microscopic examination with $20 \% \mathrm{KOH}$, and examination with Wood's lamp. ${ }^{1,2}$ In this retrospective study, it was found that all MF patients were tested for $20 \% \mathrm{KOH}$ and Wood's lamp. The $20 \% \mathrm{KOH}$ examination results showed the most common mushroom elements, spore-shaped in groups or scattered. The data showed that most of our findings were graded into grade 4, namely $96.4 \%$ in 2014 , $83.7 \%$ in $2015,81.5 \%$ in 2016 , and $96.3 \%$ in 2017. These results are similar to Jacinto-Jamara's study, which states that between 13-25 years old, the 20\% $\mathrm{KOH}$ results presented grade $4+$ as the common finding; this result is consistent with ten other studies. ${ }^{18}$

Durdu (2013) found that $81.6 \%$ of $\mathrm{KOH}$ examination results show spores. ${ }^{4}$ This study also shows that all samples have positive $\mathrm{KOH}$ results with minimum yield of grade $2+$. According to JacintoJamora, the diagnosis of MF may be given with a minimum finding of grade $>2+{ }^{1,2,12} \mathrm{KOH}$ examination may diagnose MF faster than skin biopsy and culture because Malassezia sp. only grows on media with rich fatty acids, or it can also be obtained by adding three mediums with olive oil. ${ }^{12}$ Regarding the examination using Wood's lamp, 138 (70\%) samples of this study showed positive results: bright greenish-yellow colored on $119(86.2 \%)$ patients, blue color on 19 $(13.8 \%)$ patients, and no white color. This is consistent with Sharquie's 2012 study, which states that parameters of MF diagnosis by Wood's lamp examination are positive results. On the contrary, patients with acne vulgaris would present a negative result. Not only produce bright yellow-green fluorescence color, but MF also produces bright blue or white color. ${ }^{8}$ According to Gupta (2004), Wood's lamp examination on Malassezia sp. shows yellowish-white or copper orange color. Wood's lamp can be used to detect subclinical infection or widespread infection, which may help in distinguishing the cause of folliculitis by MF or other causes. ${ }^{14}$ This is in line with Durdu's study in 2013 that involved 49 patients diagnosed with MF. The study found that the Wood's lamp examination result was $66.7 \%$ of patients produced greenish-yellow fluorescence color. Wood's lamp will result in positive on MF due to certain compounds synthesized by Malassezia.sp. called pityriacitrin and pityrialactone, which absorb light and fluoresce under ultraviolet (UV) light. ${ }^{4}$

Management or therapy was given in the case of MF in the Mycology Division Outpatient Clinic of 
Dermatology Venerology Department Dr. Soetomo General Academic Hospital Surabaya. From these data, it can be seen that in 2014, 2015, 2016, and 2017, ketoconazole was the most therapeutic option for MF treatment. Also, it was found that some cases were treated with systemic antifungal ketoconazole and $0.05 \%$ tretinoin cream. Overall, the MF therapies were in accordance with the Clinical Practice Guidelines used at Dr. Soetomo Surabaya, where ketoconazole is the first-line drug for systemic therapy of MF patients with evaluation every four weeks. ${ }^{1}$ The use of antifungal as an MF treatment had been provided satisfactory therapeutic results. A study conducted by Yu et al in 1998 stated that the use of anti-fungal therapy might reduce the spore load to less than $2+$ after two weeks of therapy. Ketoconazole reduces the rate of sebum production, preventing the blockade of the follicles' ostium. ${ }^{15}$ A total of 137 (62.54\%) MF patients did not attend the follow-up visit, 30 (22.1\%) MF patients attended the follow-up visit once and showed improvement, seven patients $(8.7 \%)$ attended the follow-up visit twice, six patients $(3.6 \%)$ attended the follow-up visit three times, and $6(3.06 \%)$ attended more the follow-up visit more than three times.

Healthcare providers shall educate and encourage MF patients to attend the follow-up visit as MF has a high possibility of recurrence. Remind MF patients always to avoid exogenous and endogenous predisposition factors that might cause MF recurrence. Patients should be counseled about how to avoid MF triggering factors including heat, moist temperatures, and excessive sweating and stopping the use of antibiotics and corticosteroids ${ }^{2.1}$

\section{REFERENCES}

1. Suyoso S, Ervianti E, Astari L. Malassezia folliculitis. In: Afif Nurul $\mathrm{H}$, editor. Panduan Praktik Klinis Bag/SMF Ilmu Penyakit Kulit dan Kelamin. Surabaya: RSUD Dr. Soetomo; 2014.h.76-8.

2. Miranda E. Folikulitis Malassezia. In: Bramono K, Suyoso S, Indriatmi W, Ramali LM, Widaty S, Ervianti E, editor. Dermatomikosis Superfisialis. Edisi ke- 2. Jakarta: Badan Penerbit FKUI; 2014. p.35-40.

3. Kundu RV, Garg A. Yeast infection: candidiasis, tinea (pityriasis versicolor), and Malassezia (Pityriasis) Folicullitis. In: L.A Goldsmith, S.I Katz, BA gilcherest, AS Paller, DJ Leffel, K Wolf, editors. Fitzpatrick's Dermatology in General
Medicine. $8^{\text {th }}$ ed. New York: The McGraw-Hill companies, Inc; 2012. P.2298-311.

4. Durdu M, Guran M, Ilkit M. Epidemiological characteristics of Malassezia folliculitis and use of the May-Grunwald-Giemsa stain to diagnose the infection. Diagn Micr Infec Dis 2013;76: 450-7.

5. Brea Prindaville, Leah Belazarian, Nikki A. Levin, Karen Wiss. Pityrosporum folliculitis: a retrospective review of 110 cases. J Am Acad Dermatol 2017; 2: 1-16.

6. Dwi Nurwulan Pravitasari, Sunarso Suyoso, Evy Ervianti. Profil Malassezia Folliculitis. Berkala Ilmu Kesehatan Kulit Kelamin 2015; 27(2): 12129.

7. Hald M, Arendrup MC, Svejgaard EL, Lindskov $\mathrm{R}$, Foged EK, et al. Evidence-based Danish Guidelines for the Treatment of Malassezia related Skin Diseases. Acta Derm Venereol 2015; 95: 1219.

8. Sharquie KE, Al-Hamdi KI, Al-Haroon SS, AlMohammadi A. Malassezia folliculitis versus truncal acne vulgaris (clinical and hystophatological study). JCDSA 2012; 2: 277-82.

9. Al-Qarqas F, Al-Aboosi M, Al-Shiyab D, Batanieh A. Using pruritus grading system for measurement of pruritus in patient with disease associated with itch. J Med J 2012; 46(1): 39-44.

10. Rubenstein RM, Malerich SA. Malassezia (pityrosporum) folliculitis. J Clin Aesthet Dermatol 2014; 7(3): 37-41.

11. Piotr B, Danuta K. Malassezia folliculitis on the neck. N Dermatol Online 2010; 1(2): 22-5.

12. Jacinto-Jamora $\mathrm{S}$, Tamesis J, Katigbak ML. Pityrosporum folliculitis in the Philippines: diagnosis, prevalence, and management. J Am Acad Dermatol 1991; 24: 693-6.

13. Heymann WR, Wolf DJ. Malassezia (pityrospora) folliculitis occuring during pregnancy. Int $J$ Dermatol 1986; 25: 49-51.

14. Gupta Kl, Singhi KM, Resident's. Wood's lamp. Indian J Derm Venereol Leprol 2004; 70: 131-5.

15. Yu HJ, Lee SK, Son SJ, Kim YS, Yang HY, Kim JH. Steroid acne vs pityrosporum folliculitis: the incidence of Pityrosporum ovale and the effect of antifungal drugs in steroid acne. Int $\mathrm{J}$ Dermatol1998; 37: 772-7.

16. Levin NA, Delano S. Evalution and treatment of Malassezia related skin disorders. Cosmet Dermatol 2011; 24(3): 137-4. 